\title{
A Short Review on Cellular Structure Design and Selective Laser Melting using Bio-compatible Ti6Al4V Material
}

\author{
Kalayu Mekonen Abate ${ }^{1,2}$, Aamer Nazir ${ }^{1,2}$ and Jeng Ywan Jeng ${ }^{1,2 *}$ \\ ${ }^{1}$ High Speed 3D Printing Research Center, National Taiwan University of Science and Technology, \#43, Sec.4, Keelung Road, \\ Taipei 106, Taiwan, ROC
}

${ }^{2}$ Department of Mechanical Engineering, National Taiwan University of Science and Technology, No. 43, Section 4, Keelung Road, Taipei 106, Taiwan, ROC

*Corresponding author: Jeng-Ywan Jeng, High Speed 3D Printing Research Center, National Taiwan University of Science and Technology, \#43, Sec.4, Keelung Road, Taipei 106, Taiwan, ROC

Department of Mechanical Engineering, National Taiwan University of Science and Technology, No. 43, Section 4, Keelung Road, Taipei 106, Taiwan, ROC

ARTICLE INFO
Received: 幽 April 04, 2020
Published: 㣰 April 21, 2020

Citation: Kalayu Mekonen Abate, Aamer Nazir, Jeng Ywan Jeng. A Short Review on Cellular Structure Design and Selective Laser Melting using Bio-compatible Ti6Al4V Material. Biomed J Sci \& Tech Res 27(1)2020. BJSTR. MS.ID.004457.

\begin{abstract}
Additive Manufacturing (AM) is one of the most significant in bio medical application to manufacture the implant for bone repairing applications. The implant has a cellular structure inside which is used in biomedical implant, that is used to allow our bone ingrowth. The implant material should be biodegradable, non-toxic, have similar biomechanical properties and have a porous. Due to this reason it is very significant important to design and produce implant with high accuracy. In this review, design cellular structure and AM technology of fabrication biomedical implant using Selective Laser Melting (SLM) process is detail reviewed. As per According to necessities of medical orthopedic applications, the choice of high quality AM technology printing technique and Ti6Al4V metal powder were surveyed. Aside from this biomedical -AM printing application, the biocompatible Ti6Al4V alloy will be broadly used in implant bone application, in addition to that used for scaffold in tissue engineering.
\end{abstract}

Abbreviations: EBM: Electron Beam Melting, SLM: Selective Laser Melting, AM: Additive Manufacturing

\section{Introduction}

In biomedical engineering, the medical orthopedic is a speedily developing multidisciplinary research area to rebuild implants and scaffolds[1] by using a biocompatible and biodegradable implant and scaffolding structure. As described early, it is very important to manufacture implants with high accuracy and precision. The implant has been manufactured using various AM methods such as SLM, Electron Beam Melting (EBM), In these methods, the smallest printable size is $50-200 \mu \mathrm{m}$ which is too small to be used for some biomedical scaffold or certain producing big in size on biomedical implant application [2].

\section{Design of Cellular Structures}

In biomedical orthopedics application, lattice structures are used as cellular implant that attempt to function of bone and mimic the structure [3]. The cellular structures can be used either asan implant or scaffold. In either case, the cellular implant ought to be designed to such an extent that its mechanical performance similar that of human bone, though considering different issues that optimized bone ingrowth. For instance, the mass transport and cell migration in our bone tissue can be controlled through well-designed ofpermeabilitycellular structure structures [4,5]. 
During the most recent two decades, a number ofesearchershave been investigated for designing cellular implant for scaffold which considered the properties of cellular implant such as biocompatibility, mechanical properties, bio-functionality and biodegradability of the cellular implant of scaffold [6-9].In this review, we focused on the design tools for cellular structure aimed for biomedical orthopedics application (Figure 1) the flow chat of design process. Generally, there are 3 types of methods used by engineers to design a suitable unit cell for a bio-medical application see in (Figure 2) examples design unit cells.

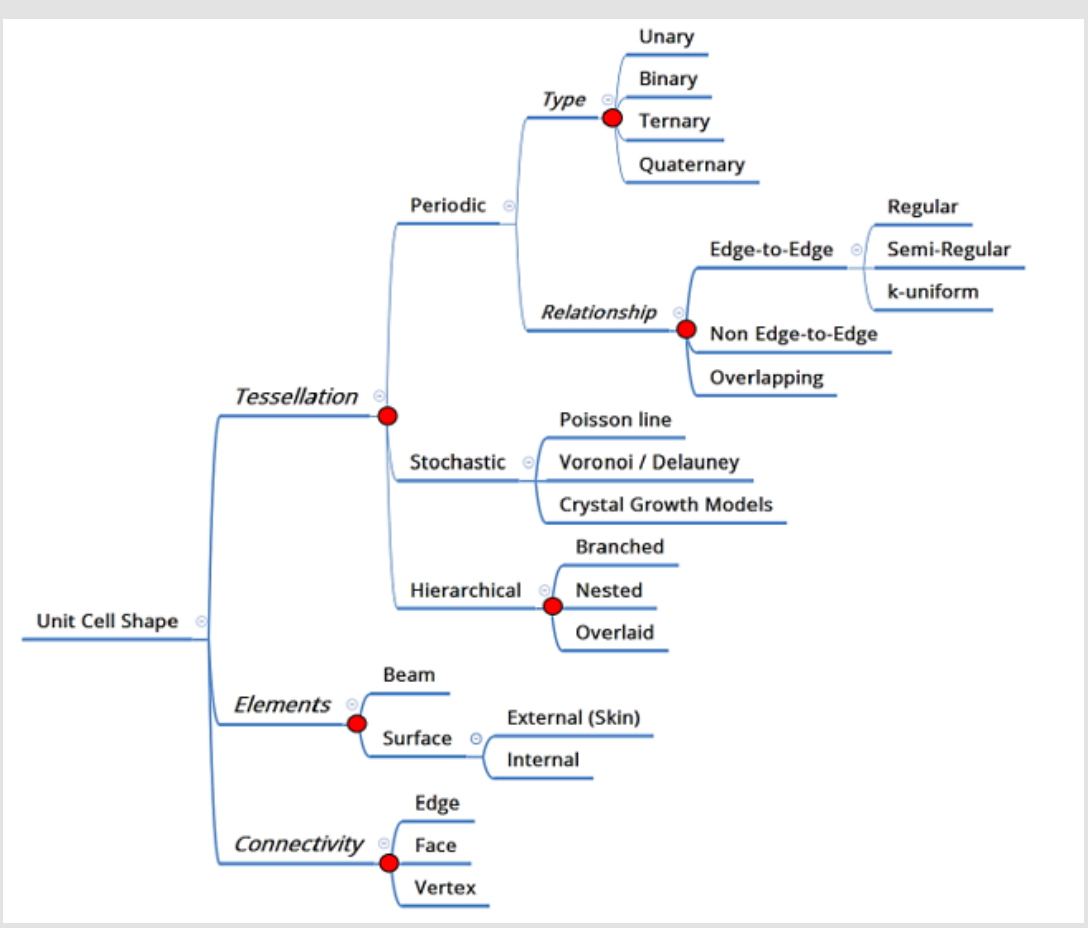

Figure 1: Flow chart for design of cellular structure [7].

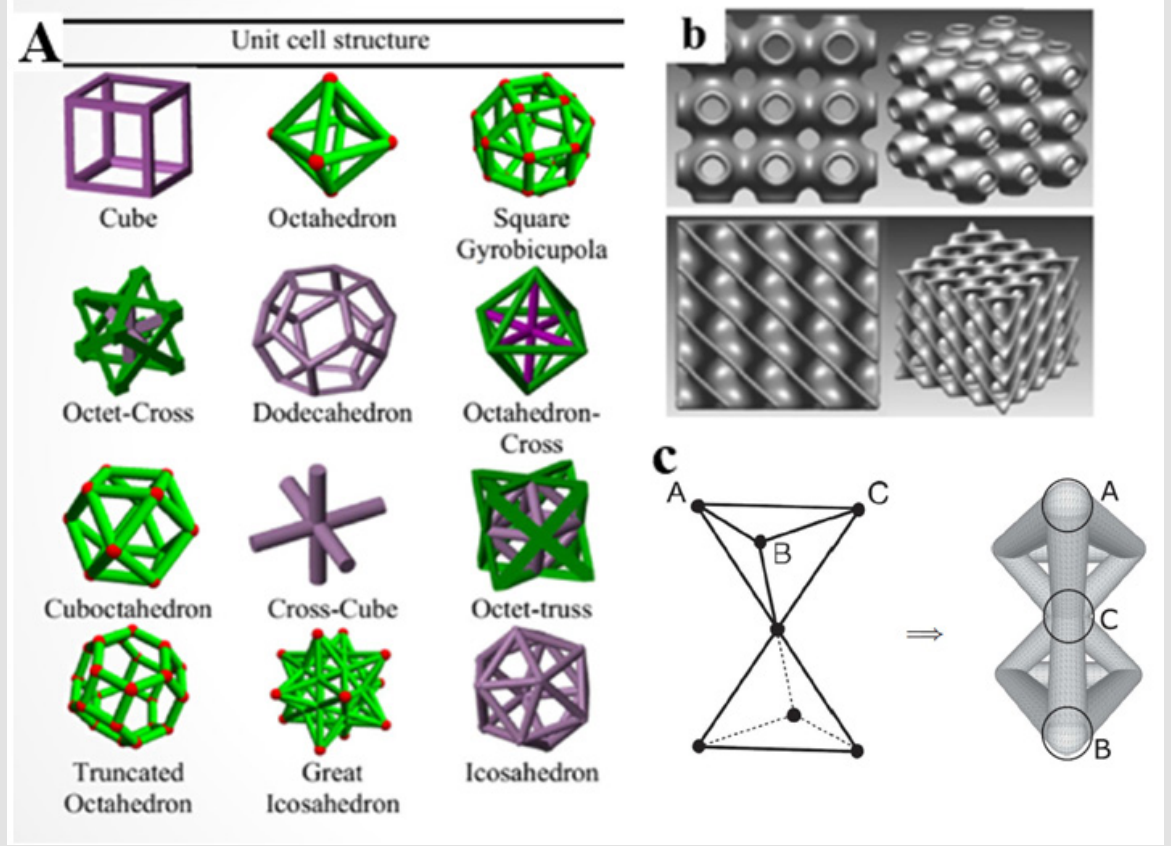

Figure 2: Methods of design of cellular structure
A. Manually generated structures,
B. Mathematical model,
C. Tessellation method $[8,9]$. 


\section{SLM Fabrication of Cellular Structures}

Based on ASTM definition of AM is "technique of joining materials to make parts by the fashion layer upon layer from STL format rather than subtractive fabrication process." As a new advanced technology since the late 1980s, therefore, due to the improvement of Additive Manufacturing innovation in biomedical applications the researchers are become more and more inserting mainly with fast growth of supercomputer technology. The development of AM technology was dependent on the computerized model by the guide of Computer Aided Design (CAD), which can solidify the powder particles layer by layer, then 3D component can be produced. The powder particles (Ti6AL4V) is usually used for cellular biomedical implant. Therefore, Additive Manufacturing technology, for example Selective Laser Melting (SLM) are generally used to fabricate Ti-6Al-4V alloys cellular implants for orthopedic application. The SLM technology the most suitable process for manufacture periodic cellular implants based on the STL file [1].

Recently, numerous studied have been used SLM process to produce cellular implant. Santorinaios, et al. investigated the fabrication of open-cell structures with a humble geometry with cross bracing and vertical struts. Brooks etal. designed and fabricated periodic cellular structures with different struts diameter and unit cell sizes using SLM process. McKown, et al.fabricated with cellular metallic implant based on lattice topologies using SLM method. The literature survey has discovered to a certain extent that SLM process of Ti6AL4V can be suitable for the manufacture of custom orthopaedic implants. The in-vivo tests results revealed that the implant made by SLM were able to allow bone growth and that SLM as an advanced fabrication technology is a promising additional to conventional implant surface topographies. On the other hand, the review has shown that cellular Ti6AL4V implant made by SLM are biocompatible, in addition to that pore size and the porosity can influence the biomedical (bone growth) and mechanical properties.

\section{Bio-Compatible Ti6Al4V}

Ti6Al4V alloys are extensively used as biomedical implant due to its many beneficial assets, such as, low stiffness, high specific strength-to-weight ratio, satisfactory biocompatibility, superior corrosion resistance, good fatigue resistance, and so on [10]. So, Ti6Al4V have been commonly used in biomedical application, such as oral repair, artificial joints, scaffold and hip implant [11-13]. The elastic modulus of Ti6Al4V is about $110 \mathrm{GPa}$, relatively low related with $\mathrm{CoCr}$ alloys and stainless steel, however very high relative to human bones (0.3-20GPa). The mismatch of stiffness between metallic implant and natural bone is a main problematic of Ti6Al4V implants in orthopedic application, that may cause stress shielding and our bone become inadequate for bearing loading. Consequently, the result of stress shielding is ultimate loosening of the implants because of the crack in our bone. Furthermore, some Ti6Al4V alloys will release toxic elements such as vanadium and aluminum, that are very hurtful to human nerves; those problems have restricted the development of Ti6Al4V in medical applications. To handle the higher stiffness of Ti6Al4V, cellular structures is progressively more developing as a technique to reduce high stiffness of titanium alloy and attain steady long-term fixation with full ingrowth bone tissue. A number of study have also investigated a number of novel titanium alloys with no harmfulness or toxicity, such as Ti6Al7Nb, which belongs to $\alpha+\beta$ type titanium alloys; Ti13Nb13Zr, Ti12Mo6Zr, Ti30ZrMo, Ti35Nb5Ta7Zr [11], and Ti-24Nb4Zr7.9Sn (Ti-2448), that similar to the novel $\beta$-type Ti alloys, to overawed the capacity toxic effects of based Titanium alloys.

\section{Conclusion}

In spite of the fact that few AM technologies are used for biomedical applications, SLM process can print cellular implant biodegradable / biocompatible implant with higher resolution and high accuracy dimension. The mechanical and biological properties are the main concern while Ti6Al4V cellular implant fabricating using SLM process.Presently, cellular metallic implant manufactured by SLM, according to in vitro biological evaluation, are not achieved very clear conclusion, this is because of design cellular implant have a lot variable such as pore shape, pore size, porosity, interconnectivity and so on. This means that any change in one variables can affect the performance of the implant. Therefore, the benefit of using permeability as variable design could the combination of the effect of the aforementioned parameters (pore size, porosity etc.) this revealed that the higher permeability implant was suitable for bone growth.

\section{References}

1. El Hachem H, Crepaux V, May Panloup P, Descamps P, Legendre G, et al. (2017) Recurrent Pregnancy Loss: Current Perspectives. Int J WomensHealth 9: 331-345.

2. Wani AA (2017) Relationship of insulin resistance with recurrent pregnancy loss. Int J ReprodContraceptObstetGynecol 6(4): 1312-1317.

3. Ibrahim Y, Johnstone E (2018) The male contribution to recurrent pregnancy loss. TranslAndrolUrol 7(Suppl 3): S317-S327.

4. Mizugishi K, Yamashita K (2017) Neutrophil Extracellular Traps Are Critical for Pregnancy Loss in Sphingosine Kinase-Deficient Mice on 129Sv/C57BL/6 Background. FASEB J 31(12): 5577-5591.

5. Shankar kumar U, Shankar kumar A, Chedda Z, Ghosh K (2011) Role of 14-bp Deletion/Insertion Polymorphism in Exon 8 of the HLA-G Gene in Recurrent Spontaneous Abortion Patients. J Hum ReprodSci 4(3): 143146.

6. Zhang TP, Tian Tian Lv, Shu Zhen Xu, Hai Feng Pan, Dong Qing Ye, et al. (2018) Association of interleukin-10 Gene Single Nucleotide Polymorphisms With Rheumatoid Arthritis in a Chinese Population. Postgrad Med J 94(1111): 284-288.

7. Zhang M, Xu J, Bao X, Niu W, Wang L, et al. (2017) Association Between Genetic Polymorphisms in Interleukin Genes and Recurrent Pregnancy Loss - A Systematic Review and Meta-Analysis. PLoS One 12(1): e0169891.

8. Pearson H (2002) Reproductive Immunology: Immunity's Pregnant Pause. Nature 420(6913): 265-266.

9. Fan DX, JieDuan, Ming Qing Li, Bin Xu, Da Jin Li, et al.(2011) The Decidual Gamma-Delta T Cells Up-Regulate the Biological Functions of Trophoblasts via IL-10 Secretion in Early Human Pregnancy. ClinImmunol 141(3): 284-292. 
10. Eskdale J, Grant Gallagher, Cor L Verweij, Vivian Keijsers, Rudi G] Westendorp, et al. (1998) Interleukin 10 Secretion in Relation to Human IL-10 Locus Haplotypes. ProcNatlAcadSci USA 95(16): 9465-9470.

11. Mörmann M, Rieth H, Hua TD, Roupelieva, Hu, et al. (2004) Mosaics of Gene Variations in the Interleukin-10 Gene Promoter Affect interleukin-10 Production Depending on the Stimulation Used. Genes Immun 5(4): 246-255.

12. Zammiti W (2006) Association of $-592 \mathrm{C} / \mathrm{A},-819 \mathrm{C} / \mathrm{T}$ and $-1082 \mathrm{~A} / \mathrm{G}$ interleukin-10 promoter polymorphisms with idiopathic recurrent spontaneous abortion. Mol Hum Reprod 12(12): 771-776.

13. Edwards Smith CJ (1999) Interleukin-10 Promoter Polymorphism Predicts Initial Response of Chronic Hepatitis C to Interferon Alfa. Hepatology 30(2): 526-530.

14. Chiusolo P, S Bellesi, N Piccirillo, S Giammarco, S Marietti, et al, (2012) The Role of HLA--G 14-bp Polymorphism in allo-HSCT After Short-Term Course MTX for GvHD Prophylaxis. Bone Marrow Transplant 47(1): 120124.

15. Kovats S, Main EK, Librach C, Stubblebine M, Fisher SJ, et al. (1990) A Class I Antigen, HLA-G, Expressed in Human Trophoblasts. Science 248 (4952): 220-223.

16. D Almeida TC (2017) Soluble Human Leukocyte Antigen -G During Pregnancy and Infancy in Benin: Mother/child Resemblance and Association With the Risk of Malaria Infection and Low Birth Weight. PLoS One 12(2): e0171117.

17. Hunt JS (2000) Soluble HLA-G Circulates in Maternal Blood During Pregnancy. Am J Obstet Gynecol 183(3): 682-688.

18. Steinborn A, Tibor Varkonyi Alexander Scharf Franz Bahlmann Andreas Klee, et al. (2007) Early Detection of Decreased Soluble HLA-G Levels in the Maternal Circulation Predicts the Occurrence of Preeclampsia and Intrauterine Growth Retardation During Further Course of Pregnancy. Am J ReprodImmunol 57(4): 277-286.

19. Rizzo R, Andersen AS, Lassen MR, Sørensen HC, Bergholt T, et al. (2009) Soluble Human Leukocyte antigen-G Isoforms in Maternal Plasma in Early and Late Pregnancy. Am J ReprodImmunol 62(5): 320-338.

20. Hviid TV (2003) HLA-G Allelic Variants Are Associated With Differences in the HLA-G mRNA Isoform Profile and HLA-G mRNA Levels. Immunogenetics 55(2): 63-79.

21. Chen XY, Yan WH, Lin A, Xu HH, Zhang JG, et al. (2008) The 14 Bp Deletion Polymorphisms in HLA-G Gene Play an Important Role in the Expression of Soluble HLA-G in Plasma. Tissue Antigens 72(4): 335-341.

22. Martelli Palomino G (2013) Polymorphic Sites at the 3' Untranslated Region of the HLA-G Gene Are Associated With Differential Hla-G Soluble Levels in the Brazilian and French Population. PLoS One 8(10): e71742.

23. Monti M, Lupoli R, Sosa Fernandez LM, Cirillo F, Di Minno MND, et al. (2019) Association of Human Leukocyte antigen-G 14 Bp Polymorphism With Recurrent Pregnancy Loss in European Countries: A Meta-Analysis of Literature Studies. FertilSteril 112(3): 577-585.

24. Rousseau P (2003) The 14 Bp Deletion-Insertion Polymorphism in the 3' UT Region of the HLA-G Gene Influences HLA-G mRNA Stability. Hum Immunol 64(11): 1005-10010.
25. Enghelabifar M (2014) Association of the Maternal 14-bp Insertion/ Deletion Polymorphism in the Histocompatibility Leukocyte Antigen G Gene With Recurrent Implantation Failure. Iran J Reprod Med 12(9): 641-646.

26. Zidi I (2016) sHLA-G1 and HLA-G5 Levels Are Decreased in Tunisian Women with Multiple Abortion. Hum Immunol 77(4): 342-345.

27. de Oliveira S, Rosowski EE, Huttenlocher A (2016) Neutrophil Migration in Infection and Wound Repair: Going Forward in Reverse. Nat Rev Immunol 16(6): 378-391.

28. Mayadas TN (2014) The Multifaceted Functions of Neutrophils. Annu Rev Pathol 9: 181-218.

29. Delgado Rizo V, Martínez Guzmán MA, Iñiguez Gutierrez L, García Orozco A, Alvarado Navarro A, et al. (2017) Neutrophil Extracellular Traps and Its Implications in Inflammation: An Overview. Front Immunol 8: 81.

30. Brinkmann V (2004) Neutrophil Extracellular Traps Kill Bacteria. Science 303(5663): 1532-1535.

31. Fuchs TA(2010) Extracellular DNA Traps Promote Thrombosis. ProcNatlAcadSci USA 107(36): 15880-15885.

32. Cools Lartigue J, Spicer J, McDonald B, Gowing S, Chow S, et al. (2013) Neutrophil Extracellular Traps Sequester Circulating Tumor Cells and Promote Metastasis. J Clin Invest 123(8): 3446-3458.

33. Park J, Amoozgar Z, Maiorino L, Fein MR, Jorns J, et al. (2016) Cancer Cells Induce Metastasis-Supporting Neutrophil Extracellular DNA Traps. SciTransl Med 8(361): 361ra138.

34. Monti M, De Rosa V, Iommelli F, Carriero MV, Terlizzi C, et al. (2018) Neutrophil Extracellular Traps as an Adhesion Substrate for Different Tumor Cells Expressing RGD-Binding Integrins. Int J MolSci 19(8): 2350.

35. Monti M, Francesca Iommelli, Viviana De Rosa, Maria Vincenza Carriero, Roberta Miceli, et al. (2017) Integrin-dependent Cell Adhesion to Neutrophil Extracellular Traps Through Engagement of Fibronectin in Neutrophil-Like Cells. PLoS One 12(2): e0171362.

36. Dörne T(2012) SLE in 2011: Deciphering the Role of NETs and Networks in SLE. Nat Rev Rheumatol 8(2): 68-70.

37. Corsiero E, Michele Bombardieri, Emanuela Carlotti, Federico Pratesi, William Robinson, et al. (2016) Single Cell Cloning and Recombinant Monoclonal Antibodies Generation From RA Synovial B Cells Reveal Frequent Targeting of Citrullinated Histones of NETs. Ann Rheum Dis 75(10): 1866-1875.

38. Hahn S (2012) Neutrophil NETs in Reproduction: From Infertility to Preeclampsia and the Possibility of Fetal Loss. Front Immunol 3: 362.

39. Hahn S (2006) Disturbances in Placental Immunology: Ready for Therapeutic Interventions? Springer SeminImmunopathol 27(4): 477493.

40. Alghamdi AS, Foster DN (2005) Seminal DNase Frees Spermatozoa Entangled in Neutrophil Extracellular Traps. BiolReprod 73(6): 11741181. 
ISSN: 2574-1241

DOI: 10.26717/BJSTR.2020.27.004457

Jeng Ywan Jeng. Biomed J Sci \& Tech Res

(C) (i) This work is licensed under Creative

Submission Link: https://biomedres.us/submit-manuscript.php

\begin{tabular}{ll} 
BIOMEDICAL & Assets of Publishing with us \\
RESEARCHES & - Global archiving of articles \\
& - Immediate, unrestricted online access \\
\hline
\end{tabular}

